\title{
The health status of the Chinese elderly and changes since 1990s: evidence from population censuses and sampling surveys
}

\author{
Wenjuan Zhang ${ }^{1} \cdot$ Dongjing Wang $^{2}$ (1)
}

Received: 26 October 2018 / Accepted: 4 January 2019 / Published online: 22 January 2019

(c) China Population and Development Research 2019

\begin{abstract}
Employing data from the population census in 2010 and the 1\% population sample survey in 2015 , this paper examines the health status of China's elderly including urban-rural differences and gender gaps in their health. In addition, sampling surveys from 1994 and 2004 are used to analyze the changes in the health status of the elderly since 1994. The results show that the health status of the urban elderly remained stable, but that of the rural elderly improved between the years 2010 and 2015. The health status of older males was generally better than that of older females. The health status of middle-aged elderly improved, but that of the oldestold declined among male groups. The prevalence of disability of the elderly declined between 1994 and 2015, but the developmental pattern of disability changed in this period.
\end{abstract}

Keywords Health status of the elderly · Self-reported health · Disability

\section{Research background}

Health is an important factor affecting the daily activities of the elderly. Good health enables elderly people to continue their adult lifestyles and remain active as they age. "Health is a state of complete physical, mental and social well-being and not

Dongjing Wang

derieswong@163.com

Wenjuan Zhang

zhwenj@263.net

1 Institute of Gerontology, Renmin University of China, Beijing, China

2 School of Sociology and Population Studies, Renmin University of China, 59 Zhongguancun Ave, Haidian District, Beijing 100874, China 
merely the absence of disease or infirmity", ${ }^{1}$ including physical health, social health, mental health, emotional health and psychological health (Li 2007). Therefore, assessing the health status of an individual or group is a complex job (Zhang and Xu 2011). Over the past several decades, self-reported health assessments by the elderly themselves have been employed to evaluate the health status of the elderly (Marja Jylhä 2009; Tang et al. 1997). These reflect the evaluations of individuals of their own health status (Jennifer et al. 2004) and are regarded as an effective and reliable comprehensive index to evaluate health status (Fredric and Robert 1992; John and Robert 1997; Thierry and Cyrille 2009; ZHENG 2000). Research findings show that differences in the health status of elderly people of different ages (Meng and Zhang 2010), from different regions (Luo and Qian 2016), and in different gender groups (Li and Li 2009) are constantly increasing. Employing data from China's Sixth Population Census in 2010 and from the self-reported health assessments of elderly people included in the $1 \%$ population sample survey in 2015 , this paper analyzes self-reported health status of the Chinese elderly and its heterogeneities. Additionally, data from earlies sampling surveys are also considered to identify changes in the health status of the Chinese elderly in recent years.

\section{Review of research}

\subsection{Validity of self-reported health}

Researchers in many developed countries have discovered that self-reported health is closely related to mortality risk (DeSalvo et al. 2006; Kaplan et al. 1996; Møller et al. 1996; Mossey and Shapiro 1982; Pijls et al.1993; Shadbol 1997) and that poor self-reported health is tightly linked to high incidence rates of chronic diseases (Tom et al. 1998), the deterioration of physical functions (Ellen et al. 2000), and high demand for health care services of the elderly (Ellen and Yael 1997). Moreover, self-reported health by elderly people can predict the diseases and deaths of those people (Mays et al. 1992; Nyboc et al. 2003; Vuorisalmi et al. 2012) and reflect changes in conditions of diseases over the long term (Galenkamp et al. 2013). In some cases, this index has been used as the standard to allocate medical and health care resources (Anna and Jennifer 2011; Birch et al. 1996).

\subsection{Relevant factors of self-reported health}

Previous research has demonstrated that there are differences in the self-reported health of elderly people, depending on their ages and genders, and the regions where they are from. Older females are more likely to suffer from certain non-fatal chronic diseases than older males of the same age group, and their self-reported health is worse than that of those males (Bath 2003). The self-reported health of individuals

\footnotetext{
${ }^{1}$ World Health Organization: Constitution of the World Health Organization [M]. 1946: 1315-1323.
} 
aged 60 and over declines greatly (Bi and Hu 2008; Dan and Jeffrey 1979; Krause and Jay 1994), and these people are likely to have lower expectations for health, which results in the elderly giving more positive self-reports of health as they age (Sheung-Tak et al. 2007). Scores of the self-reported health of the oldest-old, those aged 80 and above, are usually higher than those of contemporaries who are youngold (aged 60-69) and old-old (aged 70-79) (Ferraro 1980). The education (Kingston et al. 2003) and income levels (Subramanian and Kawachi 2004) of elderly people are positively associated with good self-reported health. Additionally, reasonable consumption of alcohol and exercise may also improve the self-reported health of elderly people (Gu and Qiao 2006). Over time, the self-reported health evaluations of individuals and groups are influenced by many external factors, such as social values (Tian 2011), living environments (Hu and Gong 2013), family relationships (Zhou et al. 2009), living arrangements (Gu and Liu 2006; Javier et al. 2008; Karine et al. 2008), life satisfaction (Zhong et al. 2016) and social participation (Lu 2017; Wei 2013). All of these factors have considerable influence on self-reported health.

\subsection{Two dimensions of health}

In the World Report on Ageing and Health 2015, WHO differentiated two aspects to healthy ageing: functional ability and intrinsic capacity (Somnath et al. 2017). Intrinsic capacity is the composite of all the physical and mental capacities of an individual, and functional ability comprises the health-related attributes that enable people to be and to do what they have reason to value. Functional ability is a property related to health that is dependent on the interactions between an individual's intrinsic capacity and relevant environmental factors (Alarcos et al. 2017). The interaction of environmental factors and intrinsic capacity finally determines whether an individual with a certain level of intrinsic capacity is capable to complete an action in a particular external environment. Intrinsic capacity is highly associated with individual conditions that reflect the bodily functions of an individual and his/her potential health status. These conditions include diseases, disorders, injuries and changes in physiological state, as well as frailty and ageing (see Fig. 1). Removing the influences of the environment, intrinsic capacity can be described in terms of functions of different fields (emotion, cognition and body) and be summed up as a single measurement of the overall health status of an individual (Sadana 2002). As an individual grows, both functional ability and intrinsic capacity increase early in life and then decrease later (see Fig. 2). The concepts of intrinsic capacity and functional ability and related factors of self-reported health revealed in previous research allow us to conclude that self-reported health is a great indicator of the intrinsic capacity of the elderly. The activities of daily living (ADL), which are influenced by an individual's living environment, are external manifestations of health in specific environments.

In summary, self-reported health is closely related both to individual factors like gender, age, levels of educational achievement and income, and to external factors such as social environments, economic development levels and urban-rural 


\section{Environments}

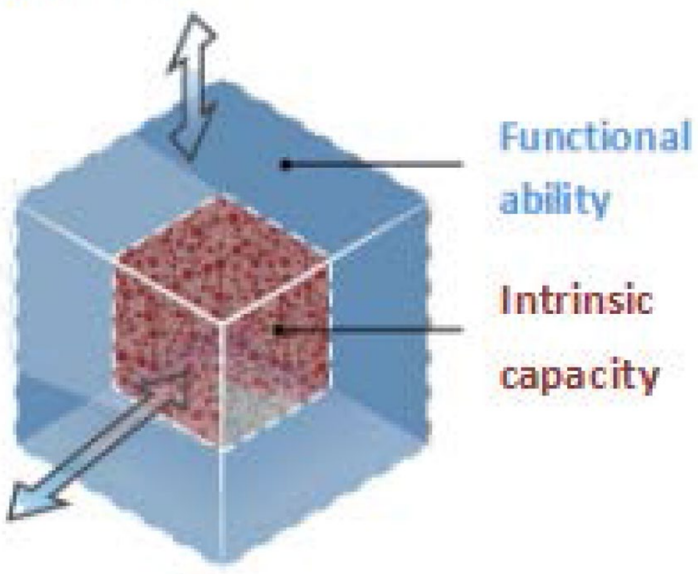

Fig. 1 Schematic diagram of healthy ageing. Picture source: World Report on Ageing and Health 2015 of WHO

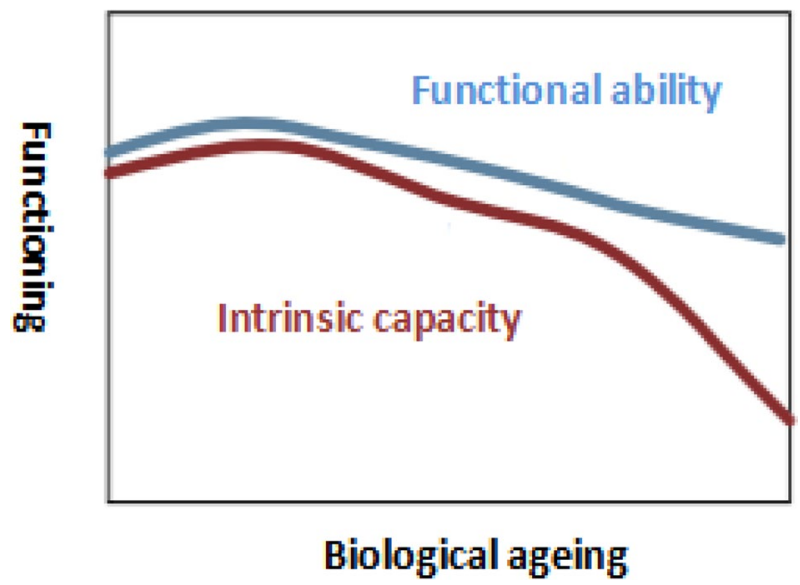

Fig. 2 Change trajectories of functional ability and intrinsic capacity. Picture source: World Report on Ageing and Health 2015 of WHO

differences (Luo and Qian 2016). However, there is little research on the longitudinal trends of self-reported health by the elderly due to limited data resources. Analyses confined to cross-sectional data are unable to completely reproduce change trajectories for an individual's health during a specific historical period. Ongoing analysis of changes to the self-reported health of the elderly at different times can better show the changing trajectories of health as individuals age and can also reveal the ageing situation of different cohorts of elderly people against a background of social change. 


\section{Methodology}

\subsection{Data sources}

The Sample Survey on Population Changes implemented by the National Bureau of Statistics in 1994 was the first of China's national population censuses and sample surveys to collect data on the self-reported health of the elderly. The survey asked elderly people whether they could care for themselves (eating, dressing, using the toilet, walking indoors and getting into and out of bed) (Zhang and Du 2009). Ten years later, the self-reported health of the elderly was included in the Sample Survey on Population Changes in 2004 and more detailed data was sought to determine the health status of the elderly (Du and Wu 2006). In 2010, the self-reported health status of the elderly was ranked into four levels: good health, fair health, poor health without disability, poor health with disability. This measurement has been used in later population consensus and sample surveys to ensure the comparability of data. This paper uses data from Sample Survey on Population Changes in 1994 and 2004, the Sixth Population Census in 2010, and the 1\% Population Sample Survey in 2015 to analyze the self-reported health information provided by the elderly.

\subsection{Research design}

The self-reported health of the elderly in recent population censuses and sample surveys takes into consideration two aspects: whether the elderly person is in good or poor health, and whether he or she is with or without disability. These two aspects, health and disability status, are adopted to analyze the self-reported health. The two dimensions mirror intrinsic capacity and functional ability as defined by the WHO World Report on Ageing and Health; that is, health status is largely a reflection of intrinsic capacity and ADL reveals the status of functional ability.

This study takes people aged 60 and above as elderly and analyzes their health employing data from the 2010 census and the $1 \%$ sample survey in 2015 . The analysis separates the elderly who reported being in poor health status into two groups: being in poor health but not disabled, and being in poor health and disabled. Trends of change are analyzed in detail by comparing the percentages of the elderly in poor health from urban and rural areas and the percentages of males and females in different age groups for the years 2010 and 2015.

Analysis of disabled status begins with data from the 1994 Sample Survey on Population Changes in 1994. The statistical standard and the definition of "disabled" has remained consistent from 1994 until the present (Lin 2015). Analysis of the dynamic change employs data from population censuses and sample surveys in 1994, 2004, 2010 and 2015, and compares the proportions of the disabled and not disabled elderly men and women in each age group. 


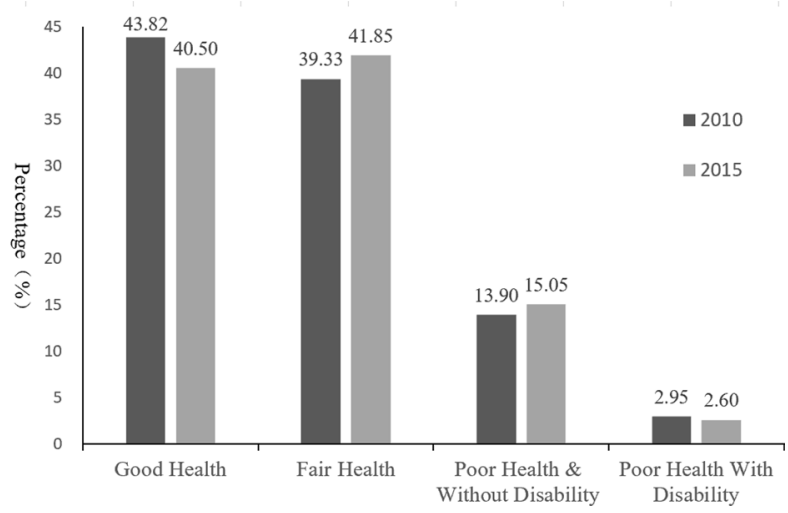

Fig. 3 Percentages of the elderly in different health status in 2010 and 2015. Data sources: these are calculated with weighted data from population census in 2010 and the $1 \%$ population sample survey in 2015

\section{Results and discussions}

\subsection{Changes of the self-reported health of the elderly in 2010 and 2015}

There were differences between the elderly's self-reported health and ADL status in 2010 and 2015 (see Fig. 3). Comparing the statuses of the two years, percentages of the elderly in the two extreme states (good health and poor health with disability) declined, but the fractions of the elderly in fair health and in poor health and without disability increased. These changes indicate that the intrinsic capacity of Chinese elderly, which is reflected by self-reported health status, weakened, but their functional ability measured by self-reported status of ADL disability improved. We speculate that the reason for this phenomenon may be that improvements in the cultural level and health knowledge of the population as a whole, a result of social development, has enabled people to pay more attention to health and makes them more sensitive to changes brought about by ageing. A "sense of relative deprivation" may be generated and this may result in more negative self-reported health (Wu and Chen 2015). On the other hand, social development has also made elderly living environments more accessible (Du and Li 2006), and this has improved the performance of ADL and enhanced the functional ability of the elderly.

The percentages of healthy elderly in all age groups in 2015 were lower than they were in 2010 (Fig. 4), but the proportion of the elderly in fair health in the age group 60-79 in 2015 was a little higher than it was in 2010. Percentages of those in poor health and without disability in all age groups were higher in 2015 than they were in 2010. Moreover, the gap between the fraction of the oldest-old who reported poor health status but without disability in 2010 and had grown in 2015. The percentages of the elderly with disabilities in 2010 and 2015 were roughly the same. Overall, the self-reported health of the elderly in the 60-79 age range had improved in 2015, as compared to 2010. The self-reported health of the oldest-old declined, but gaps in the self-reported health between different age groups among the oldest-old had 


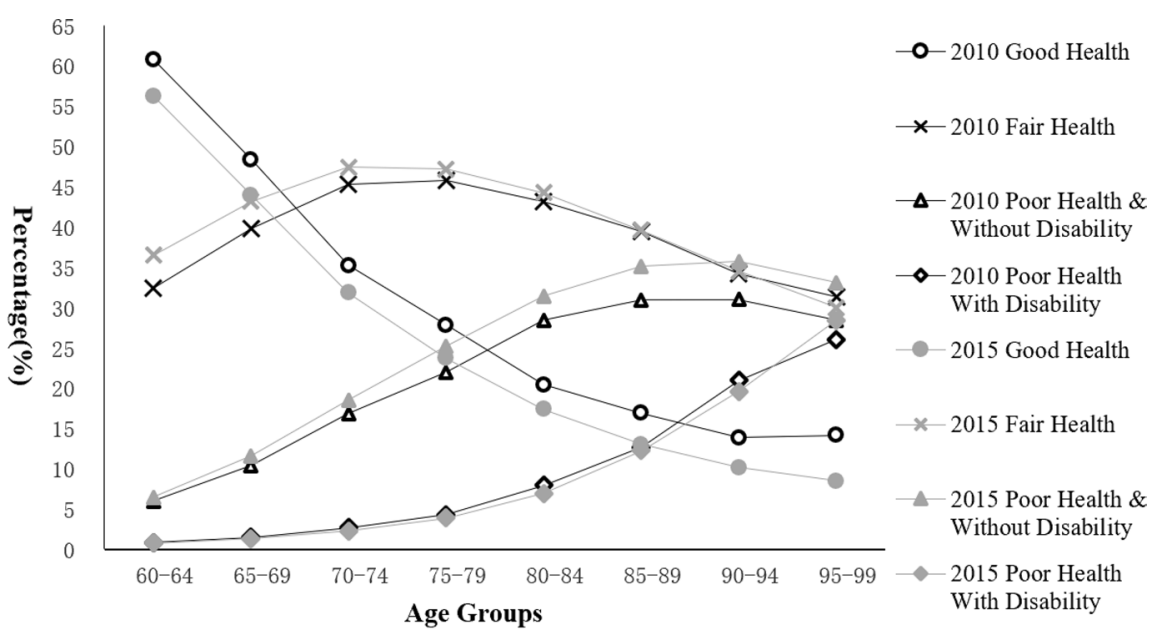

Fig. 4 Self-reported health status of the elderly by age group for the years 2010 and 2015 (percentages). Data sources: these are calculated with weighted data from population census in 2010 and the $1 \%$ population sample survey in 2015
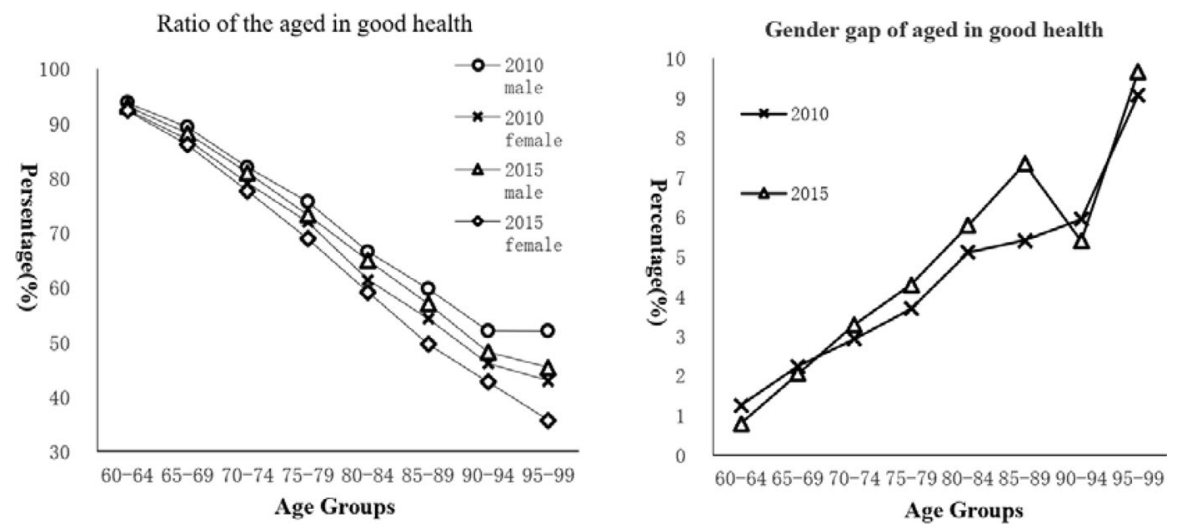

Fig. 5 Distribution and gender gaps by age groups among the elderly in good health in 2010 and 2015 . Data sources: these are calculated with weighted data from population census in 2010 and the $1 \%$ population sample survey in 2015

narrowed. A possible reason for the decline in the health of the oldest-old is the increase in longevity: people are living longer, even those with chronic diseases or disabilities (Du and Li 2006).

Figure 5 shows the distribution changes by age for the elderly in good and fair self-reported health, and compares the differences of percentage between those in good or fair health among different age groups in the years 2010 and 2015. The self-reported health of old males was better than that of old females in both 2010 and 2015. Compared with their status in 2010, the health status of the oldest-old 


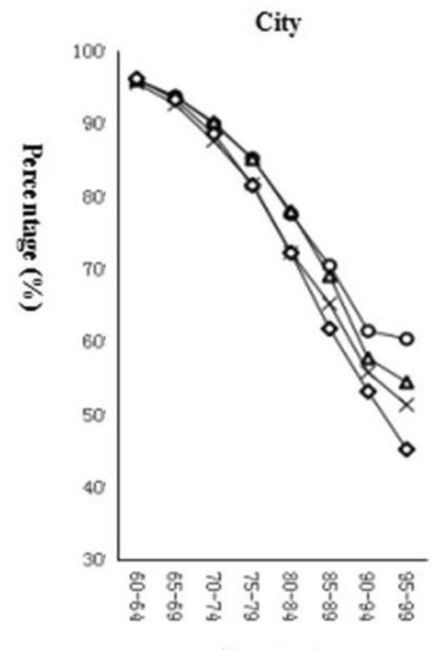

Age groups

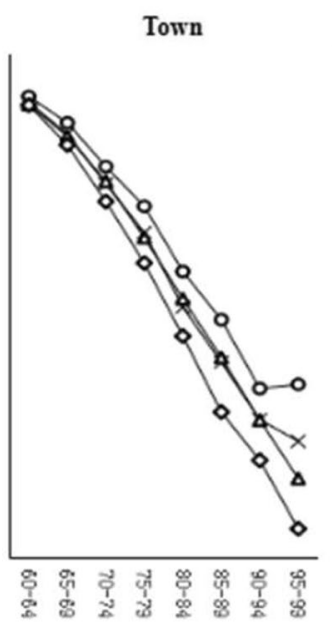

Age groups

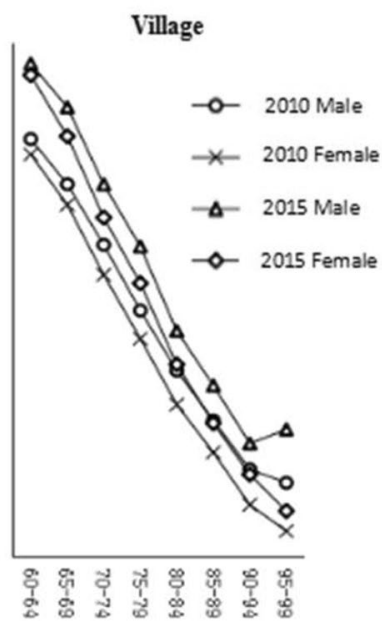

Age groups

Fig. 6 Percentages of the elderly in good health in cities, towns, and villages in 2010 and 2015. Data sources: these are calculated with weighted data from population census in 2010 and the $1 \%$ population sample survey in 2015

declined in 2015. The gender difference in the proportion of the elderly in good selfreported health among the age group 60-69 was smaller in 2015 than it was in 2010, but the gender gap in the age range 70 and above was obviously larger. These findings show that more females survive to older age than males, even in the case of the oldest-old with diseases. The findings are consistent with evidence showing that females have a survival advantage compared to males (Hao 1995). Females were often more negative than males in their self-reported health assessments, which suggests that future work on ageing should pay more attention to the health of older females.

Comparing males and females, in both 2010 and 2015 (Fig. 6), higher percentages of males in all age groups self-reported being in good health Compared with 2010 , the self-reported health of the elderly from cities and towns declined in 2015, but the self-reported health of the elderly from villages improved. It can be inferred that, although the elderly (especially those from cities) can remain in good health when they are young-old and old-old and even oldest-old, the health of the elderly in towns is likely to get worse with the decrease in mortality of the population which reduces the selective attrition among old people, and the deterioration of living environments increases the prevalence of chronic diseases in the elderly population. All of these phenomena weakened the quality of health of the Chinese elderly (Liu and Li 2013). Their needs for health care services will increase in the future. 


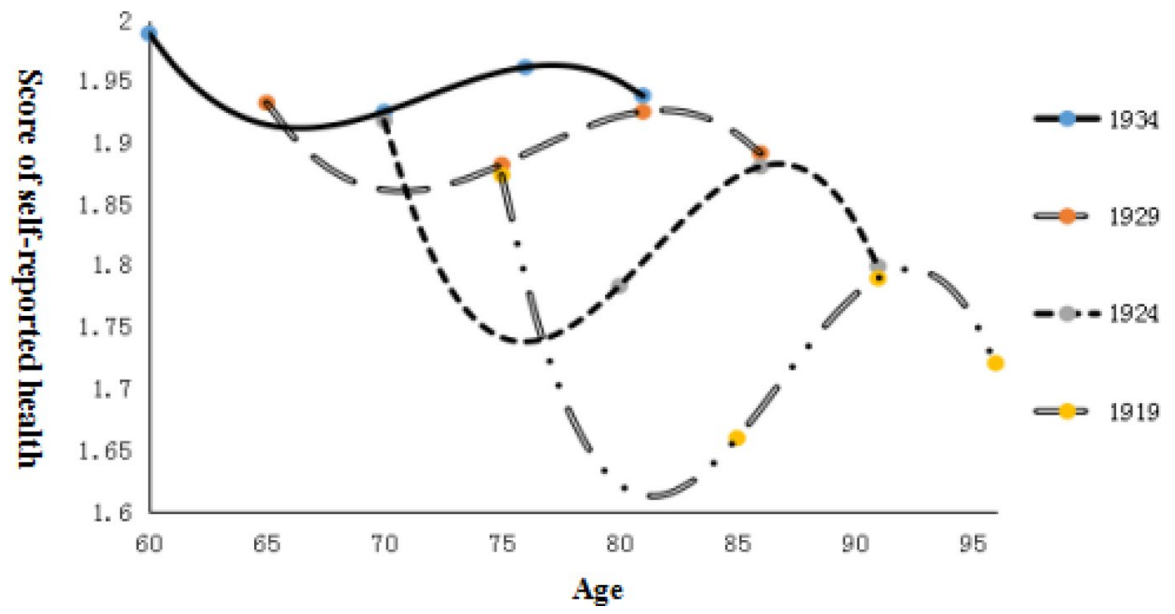

Fig. 7 Fitted curves of ADL scores for birth cohorts of 1919, 1924, 1929 and 1934. Data sources: these are calculated with weighted data from Sample Survey on Population Changes in 1994, 2004, 2010 and 2015

\subsection{Change trajectories of ADL of the elderly in 1994 and 2015}

Based on data from the years 1994, 2004, 2010 and 2015, we analyzed the change trends of ADL in birth cohorts of 1919, 1924, 1929 and 1934. The ADL of selfreported disabled elderly was assigned a value of " 1 " and that of self-reported not disabled elderly a value of "2", and the ADL scores of the cohorts for 1994, 2004, 2010 and 2015 were then calculated. Figure 7 shows that the scores of the cohort of 1934 are high and have little fluctuation. This cohort was young-old and old-old in the years 1994, 2004, 2010 and 2015, and their ADL remained good and stable, and the disability rate was low. Scores for the cohort of 1919 were the lowest and had the greatest fluctuations. Compared with the other three cohorts, the surviving members of the 1919 cohort were already among oldest-old group in 1994, their ADLs declined rapidly, and the overall ADL level was low and unstable. Comparisons of scores for the same age groups in different cohorts show that the ADL scores of the elderly in later birth cohorts were generally higher than those in earlier cohorts. A reasonable explanation is that progress in medical and health technologies, and especially improvements in living conditions, are helping to delay the process of functional decline of the elderly. These changes support the functional abilities of the elderly and enhance their ability to participate in social activities. These dynamic changes suggest that, with the progress of healthy ageing, the young-old and old-old and even some of the oldest-old will be able to remain socially capable, laying a solid foundation for active and successful ageing.

Comparing changes in the curves of ADL disability rates of the elderly by age group in 1994, 2004, 2010 and 2015 (Fig. 8), it can be seen that disability rates for all age groups were lower to some degree in 2010 and 2015 than they were in 1994 and 2004. The disability rates of the old-old and the oldest-old declined more rapidly. As they grew older, the disability rate of the elderly continued to rise. Data 

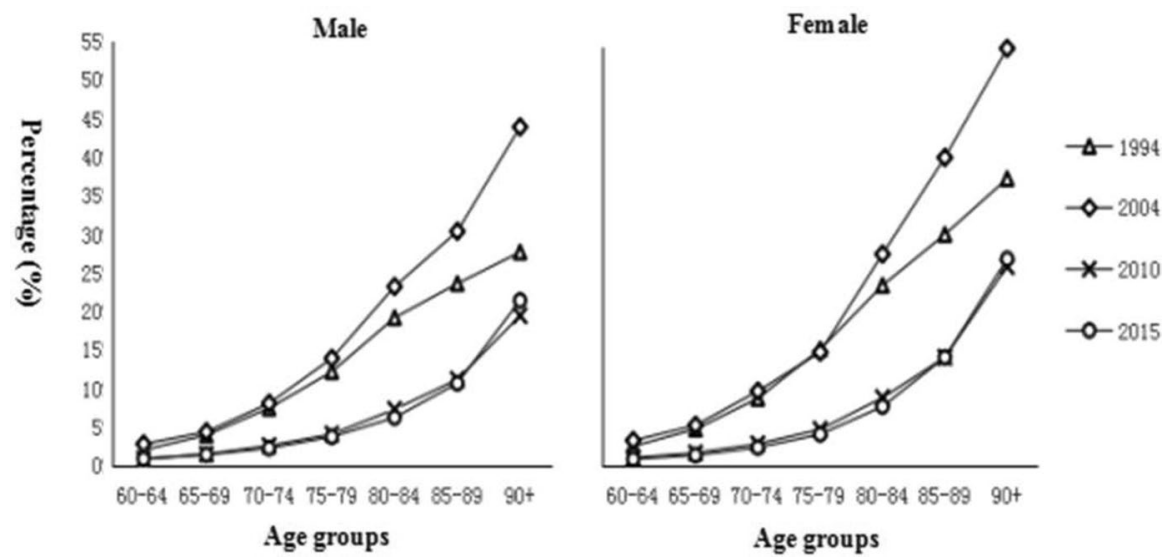

Fig. 8 Changing trends of the ADL disability rate of male and female elderly in 1994, 2004, 2010 and 2015. Data sources: these are calculated with weighted data from Sample Survey on Population Changes in 1994, 2004, 2010 and 2015

from the four surveys used in this paper show that elderly males were at less risk of disability than elderly females; there was no significant change to this pattern. Moreover, the degree of fitting of disability rates was not high in the four periods according to the change curves for age groups; the patterns of change over time were also different. It remains to be verified whether such changes should be attributed to transformations brought about by social development.

However, when ADL change trends for different birth cohorts are examined, it is clear that the ADL abilities of China's elderly improved during the years 1994-2015. Furthermore, comparing change between the years 1994 and 2004 with the difference in 2010 and 2015, the curves showing the change in the fraction of disabled elderly are not as sharp as they are in the earlier period, while the disability risk among the nonagenarians rises sharply. Such changes are in line with the "healthy ageing" policy guidelines in place since 1990, which aim to promote the physical and mental health of the elderly and reduce the amount of time the elderly suffer from diseases during the final stage of life. On the whole, in the period of years 1994-2004, disability risks of the young-old and old-old groups increased, and this may be due to the progress in the medical and health care systems and improvements in living conditions which have enabled more elderly people to survive with diseases and disabilities. Using mortality risk as an indicator, it is clear that intrinsic capacity has improved, but no corresponding improvement in functional ability measured by ADL can be seen. During the years 2005-2015, living conditions improved as did medical care services and rehabilitation technologies. As the society began paying more attention to the quality of life of the elderly, their intrinsic capacity improved and survival time increased while the survival period with disabilities was compressed to the end of life. 


\section{Conclusion}

The comprehensive analyses presented in this paper show that the change trends for the health of China's elderly have become more complex. The changes in ADL during the 20 years from 1994 to 2015 demonstrate that there were obvious improvements to the health status of China's elderly during this period, and that the percentage of disabled elderly declined. Moreover, the ADL change trends for different birth cohorts reveal that the status of functional ability of the elderly also changed during the years 1994 to 2015. At the end of the period, the decline of functional ability of elderly individuals generally began at an older age than it did at the beginning of the period. The process of individual ageing also may have changed. The fundamental driving force of these transformations was socioeconomic development. The improvements in living conditions the elderly achieved as a result of social development supported the elderly's increased functional capacities, and enhancements of medical care and rehabilitation technologies have helped to reduce the deterioration of ADL from ageing and disease, allowing elderly people to maintain their functional abilities at optimal status for a longer period of time. However, in terms of more recent developments, the self-reported health of the elderly in 2010-2015 was more stable than it was before 2010, and heterogeneity declined. In these years, the percentages of elderly self-reporting good health or poor health and disabled declined, while the percentage of elderly self-reporting fair health or poor health and without disability increased. These changes suggest that the selective effect of death weakened due to improvements in medical care services and that the age-friendly living conditions of the elderly improved their functional health.

Research findings also show that there are still great differences in the health status of urban and rural elderly. This reflects gaps in the physical health of the elderly and the influences of social factors on quality of life. There are sufficient medical and health care resources in urban areas and urban residents have high accessibility to such resources. Also, the education and income of urban elderly are generally higher than those of rural elderly. These factors increase the purchasing power of urban elderly to medical services, and lead to high acceptance and utilization of information about medical and health care. Though changes in the health of the elderly from towns are not obvious, the health of those from villages has improved since 2010. Although the rural elderly lag behind urban elderly in terms of health conditions, the urban-rural divide is showing a tendency to narrow. This may be attributable to the promotion of integrated social security systems serving both urban and rural people, and the apparent improvement in living environments resulting from new rural construction. Gender gaps in both towns and villages still exist and the self-reported health and ADL of old males is generally better than those of females. Many factors are responsible for gender gaps. Elderly males generally have higher education and income than females, and thus are more likely to self-report good health. At the same time, elderly females are more likely to suffer from chronic diseases with low mortality rates like rheumatoid arthritis (Molarius and Janson 2003), and have greater risks of cognitive impairment and dysfunction than elderly men. Moreover, 
elderly females often choose to under-report their actual conditions in health surveys (Spiers et al. 2003).

These conclusions lead us to infer that if we evaluate health inequality in the ageing process with the self-reported health of surviving elderly, the health inequality among the elderly prevails and shows high diversity such as urban-rural gaps and gender differences. However, improvements to the health of the elderly brought about by social development may show different trends of change for intrinsic capacity and external functional ability of surviving elderly. On the one hand, decrease in mortality risk arising from social progress weaken the selective effect of death. More elderly people suffering from diseases can survive longer to become old-old or even oldest-old, and because people survive longer, this shows as the weakening of the health of surviving elderly, especially their intrinsic capacity. On the other hand, the improvement of living environments and increasingly "age-friendly" socioeconomic development means that less demands are made of the intrinsic capacity of elderly people engaged in daily activities. Also the functional ability of the elderly continues to expand and improve, with disability risks lessening and functional decline occurring later in the ageing process. Therefore, analyses of comprehensive indexes of health and the application of findings should be undertaken with great caution.

Funding This study is supported by "A Study on the Elderly Care System in China in the View of Healthy Ageing" (17XNLG08), a major planning project of scientific research fund of Renmin University of China.

\section{References}

Alarcos, C., Kaloyan, K., Alana, O., Anne-Margriet, P., \& Megumi, R. (2017). Towards operationalizing functional ability. Geneva: World Health Organization.

Anna, Z., \& Jennifer, B. D. (2011). Reliability of self-rated health in US adults. American Journal of Epidemiology, 174(10), 977-983.

Bath, P. A. (2003). Differences between older men and women in the self-rated health-mortality relationship. The Gerontologist., 43(3), 387-395.

Bi, Q., \& Hu, J. (2008). Research on the self-reported healthy life expectancy of Chinese population. Chinese Journal of Health Statistics., 4(25), 151-153.

Birch, S., Eyles, J., \& Newbold, B. (1996). Proxies for healthcare need among populations: Validation of alternatives-A study in Quebec. Journal of Epidemiology and Community Health, 50, 564-569.

Dan, G. B., \& Jeffrey, L. H. (1979). Perception of poor health in the healthy older adult. Journal of the American Geriatrics Society, 7, 330-334.

DeSalvo, K. B., Bloser, N., Reynolds, K., He, J., \& Muntner, P. (2006). Clinical review: Mortality prediction with a single general self-rated health question. Journal of General Internal Medicine, 21(3), 267-275.

Du, P., \& Li, Q. (2006). Disability-free life expectancy of Chinese elderly and its change between 1994 and 2004. Population Research., 5, 9-16.

Du, P., \& Wu, C. (2006). Conditions and changes in activities of daily living among Chinese elderly. Research on Ageing., 1, 50-56.

Ellen, L. I., Louise, B. R., \& Diane, D. (2000). Survival, functional limitations, and self-rated health in the NHANES I Epidemiologic Follow-up Study. American Journal of Epidemiology., 9, 874-883.

Ellen, L. I., \& Yael, B. (1997). Self-rated health and mortality: A review of twenty seven community studies. Journal of Health and Social Behavior., 38, 21-37.

Ferraro, K. F. (1980). Self-ratings of health among the old and the old-old. Journal of Health and Social Behavior, 21, 377-383. 
Galenkamp, H., Deeg, D. J. H., Huisman, M., Hervonen, A., Braam, A. W., \& Jylhä, M. (2013). Is self-rated health still sensitive for changes in disease and functioning among nonagenarians? Journals of Gerontology. Series B, Psychological Sciences and Social Sciences, 5, 848-858.

$\mathrm{Gu}, \mathrm{D} .$, \& Liu, Y. (2006). Comparative research on the health and mortality risk of the elderly cared by institutions and those by families in China. Population Research., 9, 49-56.

Gu, L., \& Qiao, X. (2006). Analysis on influencing factors of self-reported health of Chinese elderly. Population Journal., 6(1), 25-29.

Hao, H. (1995). The gender mortality difference in China since the 1980s. Chinese Journal of Population Science., 2, 2-11.

Hu, Y., \& Gong, L. (2013). Analysis on influencing factors of self-reported health of the elderly in rural areas. Chinese Journal of Health Statistics., 4, 232-234.

Javier, D., Roberto, P. B., \& Emiliana, V.-G. (2008). Factors associated with self-rated health in older people living in institutions. BMC Geriatrics., 2, 1-6.

Jennifer, D. W., Colleen, J. M., David, B. H., \& Erika, M. E. (2004). Does self-rated health predict survival in older persons with cognitive impairment? Journal of the American Geriatrics Society., 11, 1895-1900.

John, W. R., \& Robert, L. K. (1997). Successful aging. The Gerontologist., 4, 433-440.

Kaplan, G. A., Goldberg, D. E., Everson, S. A., Cohen, R. D., Salonen, R., Tuomilehto, J., et al. (1996). Perceived health status and morbidity and mortality: Evidence from the Kuopio is chemic heart disease risk factor study. International Journal of Epidemiology, 4, 259-265.

Karine, H., Stefano, C., \& Myriam, G. (2008). Health perception and health status in advanced old age: A paradox of association. Journal of Aging Studies., 8, 282-290.

Kingston, P. W., Hubbard, R., \& Lapp, B. (2003). Why education matters. Sociology of Education, 76, 53-70.

Krause, N. M., \& Jay, G. M. (1994). What do global self-rated health items measure? Medical Care, 9, 930-942.

Li, H. (2007). Health psychology (p. 445). Wuhan: Wuhan University Press.

Li, J., \& Li, Y. (2009). Analysis on health disparities of Chinese elderly in view of gender. Research on Ageing., 3, 48-57.

Lin, B. (2015). An Analysis on the status and trend of old population without self-care ability in China. Population \& Economics., 25(4), 77-84.

Liu, X., \& Li, L. (2013). Survey on conditions of chronic diseases of the elderly in cities and villages of Heilongjiang Province. Chinese Journal of Public Health Management., 8(4), 499-501.

Lu, J. (2017). Empirical analysis on the interaction effect between social participation and selfreported health among the elderly in Chinese mainland-based on the verification on CLHLS data. Population Research., 1, 15-26.

Luo, H., \& Qian, J. (2016). Analysis on the influencing factors of self-reported health of the elderly in the view of regional differences. Journal of Sichuan University (Medical Science Edition)., 2(23), 248-252.

Marja, J. (2009). What is self-rated health and why does it predict mortality? Towards a unified conceptual model. Social Science \& Medicine., 8, 307-316.

Mays, N., Chinn, S., \& Mui, H. K. (1992). Interregional variations in measures of health from the Health and Lifestyle Survey and their relation with indicators of health care need in England. Journal of Epidemiology and Community Health, 46, 38-47.

Meng, Q., \& Zhang, T. (2010). Analysis on the influencing factors of self-reported health of the elderly. Journal of Peking University (Health Sciences)., 3, 258-263.

Molarius, A., \& Janson, S. (2003). Self-sated health and mortality enduring? Results from three birth cohorts in Melton Mowbray, United Kingdom. The Gerontologist., 43(3), 406-411.

Møller, L., Kristensen, T. S., \& Hollnagel, H. (1996). Self-rated health as a predictor of coronary heart disease in Copenhagen, Denmark. Journal of Epidemiology and Community Health, 50, 423-428.

Mossey, J. M., \& Shapiro, E. (1982). Self-rated health: A predictor of mortality among the elderly. Public Health., 72(8), 800-808.

Nyboc, H., Petersen, H. C., Gaist, D., Jeune, B., Andersen, K., McGue, M., et al. (2003). Predictors of mortality in 2,249 nonagenarians: the Danish 1905-Cohort Survey. Journal of the American Geriatrics Society, 10, 1365-1373.

Pijls, L. T., Feskens, E. J., \& Kromhout, D. (1993). Self-rated health, mortality, and chronic diseases in elderly men: the Zutphen Study, 1985-1990. American Journal of Epidemiology, 11, 840-848. 
Robert, Fredric D. W., \& Johnson, J. J. (1992). Perceived health status and mortality among older men and women. The Journals of Gerontology, Series B: Social Sciences., 11, 304-312.

Sadana, R. (2002). Development of standardized health state descriptions. In C. J. L. Murray, et al. (Eds.), Summary Measures of Population Health: Concepts, Ethics, Measurement and Applications 315-328. Geneva: World Health Organization.

Shadbol, B. (1997). Some correlates of self-rated health for Australian women. American Journal of Public Health, 6, 951-956.

Sheung-Tak, C., Helene, F., \& Alfred, C. (2007). Maintaining self-rated health through social comparison in old age. The Journals of Gerontology. Series B, Psychological Sciences and Social Sciences., 9, 277-285.

Somnath, C., Felix, C., \& Emese, V. (2017). Intrinsic C-how to operationalize it at a population level, criteria for measurement and monitoring over time, and key gaps. Geneva: World Health Organization.

Spiers, N., Jagger, C., Clarke, M., \& Arthur, A. (2003). Are gender differences in the relationship between self-rated health and motility enduring? Result from three birth cohorts in Melton Mowbray, United Kingdom. The Gerontologist., 43(3), 406-411.

Subramanian, S. V., \& Kawachi, I. (2004). Income inequality and health; what have we learned so far? Epidemiologic Reviews, 1, 78-91.

Tang, Z., Wu, X., \& Meng, C. (1997). Analysis of death prediction with health evaluation index of the elderly. Chinese Journal of Gerontology, 17(4), 194-196.

Thierry, L., \& Delpierre, C. (2009). 'How are you?': What do you mean? European Journal of Public Health, 6, 19.

Tian, L. (2011). Self-reported health of the elderly in Nanjing City and analysis on the influencing factors. Chinese Journal of Gerontology, 9, 3337-3340.

Tom, R. D., Lin-yang, C., Carol, B., Felicia, A. H., Eugene, S. P., \& Daniel, W. O. C. (1998). Changes in self-rated health, disability and contact with services in a very elderly cohort: A 6-year follow-up study. Age and Ageing., 27(1), 23-33.

Vuorisalmi, M., Sarkeala, T., \& Jylhä, M. (2012). Among nonagenarians, congruence between self-rated and proxy-rated health was low but both predicted mortality. Journal of Clinical Epidemiology, 65, 553-559.

Wei, X. (2013). Analysis on the influencing factors of self-reported health of Chinese elderly. Journal of Nanjing College for Population Programme Management., 10, 9-15.

World Health Organization. (2015). World report on ageing and health (pp. 28-32). Geneva: World Health Organization.

Wu, Q., \& Chen, Y. (2015). How does the status identification influence self-reported health-A research based on an eight-year national survey data. Social Sciences in Nanjing., 7, 60-68.

Zhang, W., \& Du, P. (2009). Regional disparity in changes of healthy life expectancy of Chinese elderly: Expansion or compression? Population Research., 5, 68-76.

Zhang, Y., \& Xu, L. (2011). Brief introduction of health related quality of life and its international applications. Chinese Journal of Health Informatics and Management., 4, 42-44.

Zheng, X. (2000). Research on the health evaluation index of Chinese elderly. Journal of Peking University (Philosophy \& Social Sciences)., 4(37), 144-151.

Zhong, S., Wang, W., Chai, Y., \& Lu, Z. (2016). Self-reported health of the elderly in Shiyan City, the survey on influencing factors and path analysis. Chinese General Practice., 19(27), 3356-3360.

Zhou, C., Chu, J., Xu, L., Qin, X., Chen, R., \& Hu, Z. (2009). Self-reported health of empty-nested elderly in rural areas and analysis on the influencing factors. Chinese Journal of Public Health., 5, 559-561. 

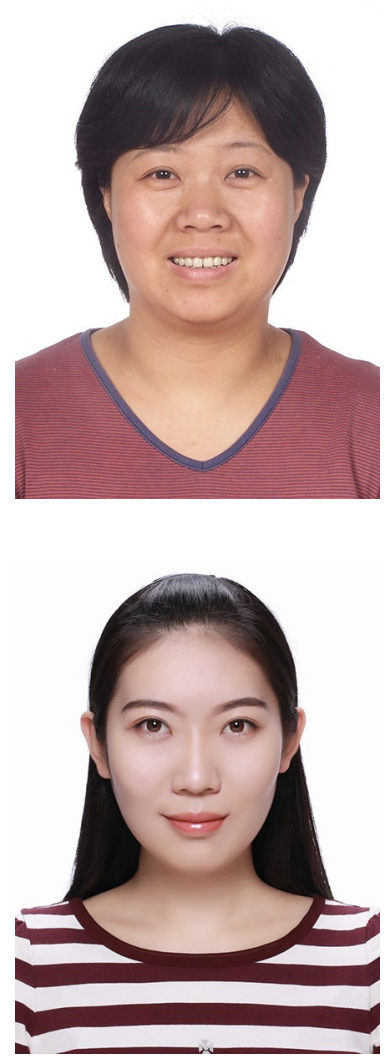

Wenjuan Zhang is a doctor of management, associate professor of School of Sociology and Population Studies, Renmin University of China. Her research field is the economics of aging and the health of aging.

Dongjing Wang is a doctor degree candidate of school of Sociology and Population Studies, Renmin University of China. Her research field is the health of aging. 